\title{
Mídia, controle social e criminalização da juventude
}

\author{
Media, social control and criminalization of youth
}

\section{Anna Carolina de Oliveira Azevedo* Rômulo Magalhães Fernandes**}

\begin{abstract}
Resumo:
O presente artigo trata do papel da mídia, tendo em vista a tendência do expansionismo penal e a criminalização da juventude. Atualmente, o continente latino-americano, e o Brasil, especificamente, vive um contexto de violência que pressiona os diferentes setores do Estado na busca de novas alternativas de controle social. Essas saídas, na maioria das vezes, são cunhadas pelo pragmatismo e pela desconsideração das verdadeiras raízes do problema. Nessa perspectiva, aborda-se a questão a partir de uma metodologia teórica, consistente em revisão bibliográfica, com ênfase na doutrina latino-americana, que abarca, sobretudo, institutos da Sociologia Jurídica, da Criminologia Crítica e do Direito Penal.
\end{abstract}

Palavras-chave: Criminologia crítica; Expansionismo penal; Juventude; Mídia.

\begin{abstract}
:
This article deals with the role of the media, in view of the tendency of criminal and expansionism the criminalization of youth. Currently, the Latin American continent, and the Brazil specifically, live a context of violence that presses the various State sectors in the search for new alternatives of social control. These outputs, for the most part, are minted by the pragmatism and the disregard of the real root of the problem. In this perspective, discusses the issue from a theoretical methodology, consistent in literature review, with emphasis on Latin American doctrine, which above all institutes of Legal Sociology, Critical Criminology and Criminal Law.
\end{abstract}

Key words: Critical criminology; Criminal expansionismo; Youth; Media.

\section{Introdução}

O atual contexto de violência e de insegurança do continente latino-americano pressiona os diferentes setores do Estado e da sociedade na busca de novas alternativas de controle social.

\footnotetext{
*Controladoria-Geral do Estado de Minas Gerais. E-mail: annac.azevedo@hotmail.com

**Pontifícia Universidade Católica de Minas Gerais. Mestrando do Programa de Pós-Graduação Stricto Sensu em Direito Público. E-mail: romulopn@yahoo.com.br
} 
Contudo, na maioria das vezes, essas saídas são cunhadas pelo pragmatismo e pela falta de interesse em modificar as verdadeiras raízes do problema, demonstrando-se ineficientes, arbitrárias e injustas.

A grande mídia, em especial a televisiva, apresenta o fenômeno da violência de forma isolada, desconsiderando a profundidade do tema. Os índices determinantes da criminalidade, tais como a distribuição de renda e o acesso a direitos sociais básicos, são ignorados. O que se percebe é o privilégio da notícia do espetáculo, do fácil convencimento, da dramatização da violência e da superficialidade.

Com isso, forma-se uma opinião pública capaz de ecoar o discurso dos segmentos mais conservadores da sociedade, que esperam do Estado, tanto na sua dimensão administrativa quanto na legislativa, um conjunto de ações que acarretem a redução do Estado Social e o aumento do Estado Policial, Penal e Penitenciário (MUÑOZ CONDE, 2005, p. 2).

O Estado responde ao problema da criminalidade com mais violência, privilegiando o policiamento ostensivo, a construção de presídios de segurança máxima, a criminalização de novas condutas, a aplicação de penas com maior rigor e a redução da idade penal.

A juventude não fica imune a esse processo. Exemplo disso é a grande visibilidade dada aos delitos de adolescentes na condição de autores de crimes, o que gera na sociedade conclusões falsas e simplistas: os jovens não são punidos; a legislação protege em demasia as crianças e os adolescentes; e a redução da idade penal é capaz de diminuir a violência nos diferentes países.

Tais visões precisam ser entendidas num contexto mais amplo, no qual se identifica uma tendência mundial de expansão do direito penal e de alternativas mais punitivas. Esse expansionismo penal, não exclusivo ao Brasil, guarda certa perversidade, pois apresenta à sociedade soluções apenas simbólicas e aparentes, utilizando-se da mudança isolada da legislação, em vez de enfrentar com real profundidade os problemas sociais que assolam o país. Sem dúvida, essa alternativa é "menos trabalhosa" para os gestores públicos, assim como mais conveniente àqueles que não têm o menor interesse de modificar o "atual estado de coisas", no qual permanecem na condição de privilegiados. 
Este trabalho não considera a aplicação do Direito Penal algo inquestionável, mas sim procura investigar "como", "por que" ou "para quem" elaborou-se determinada legislação criminal (BATISTA, 2007, p. 33).

Assim sendo, a presente pesquisa almeja inserir o debate da mídia e das formas de controle social da juventude num determinado contexto histórico, para investigar o discurso penal que mascara a realidade com a falsa ideia de igualdade e de neutralidade contida no sistema jurídico vigente (BATISTA, 2007, p. 33).

Para tanto, utiliza-se de metodologia teórica consistente em revisão bibliográfica, com ênfase na doutrina latino-americana, que abarca, sobretudo, institutos da Sociologia Jurídica, da Criminologia Crítica e do Direito Penal.

\section{Expansionismo do Direito Penal}

No texto Novas tendências do Direito Penal, Nilo Batista (2003) apresenta um estudo crítico sobre as tendências atuais do sistema penal, relacionando dados sociais, políticas criminais e os eixos centrais da legislação penal.

Inicialmente, ele caracteriza o quadro de transição histórica do Brasil e as consequências da adoção de medidas influenciadas pelo neoliberalismo:

\footnotetext{
O empreendimento neoliberal implica o sucateamento da considerável parcela "não competitiva" do parque industrial nacional, gerando desemprego massivo e obrigando esse proletariado, náufrago do mundo industrial, a se agarrar a subempregos ou buscar estratégias de sobrevivência na economia informal. 0 corte nos programas assistenciais públicos, gradualmente substituídos por planos de saúde ou previdenciários privados para o que resta da classe média, e, para os pobres, por essa caridade virtual que passa seu pires nos intervalos comerciais da televisão, quando não é o próprio Estado a conceder a esmola como "bolsa" ou "cidadania", o corte nos programas assistenciais públicos representa o fechamento de saídas de incêndio (BATISTA, 2003, p. 20).
}

Na visão do autor, a orientação das políticas socioeconômicas no Brasil baseadas na linha neoliberal - mínimo de intervenção estatal na economia e, consequentemente, na vida em sociedade - demonstra um discurso contraditório e uma realidade de desigualdades nocivas ao povo brasileiro, ou, pelo menos, à sua maior parte.

Nilo Batista (2003, p. 21) exemplifica a contradição de tal política traçando um paralelo entre o "estado mínimo" (frágeis programas sociais e o descumprimento de 
direitos sociais básicos da maioria da população) e o "estado máximo" (instrumentos que garantem o controle social penal e a manutenção da situação de desigualdade).

\begin{abstract}
O movimento de mutilação institucional que desaguará no estado mínimo dos sonhos neoliberais tem, contudo, uma consequência: este estado mínimo precisa preservar e ampliar o controle social penal sobre os contingentes humanos marginalizados e desassistidos por suas políticas econômicas e pelos cortes que a busca deste paraíso que parece existir no equilíbrio orçamentário lhe impôs. Ou seja: o estado mínimo acaba sendo um estado máximo, apenas do ponto de vista da expansão de seu sistema penal, até quase coincidir com ele (BATISTA, 2003, p. 21).
\end{abstract}

A produção flexível dos tempos neoliberais pressupõe um Estado fraco socialmente, "que não imponha amarras econômicas às grandes corporações transnacionais e aos capitais especulativos, mas que esteja apto a reprimir a população mantida em condições de vida miseráveis" (JINKINGS, 2007, p. 10).

Trata-se da consolidação de uma "sociedade de riscos", cujos aspectos mais proeminentes são o progresso tecnológico, o desenvolvimento do conhecimento e a força dos "poderosos" num mundo dominado pelas leis do mercado e da eficiência econômica (DINIZ NETO, 2010, p. 202).

Nesse contexto, tem-se a tendência, em curso no Brasil, da expansão de regras, leis e instituições de controle social penal.

Jesús-María Silva Sánchez (2002, p. 21) afirma que existe, na modernidade, uma tendência de expansão do caráter punitivista do Direito Penal, em que a globalização é vista como um dos principais fatores desse crescente recrudescimento jurídico.

\begin{abstract}
Não é nada difícil constatar a existência de uma tendência claramente dominante em todas as legislações no sentido da introdução de novos tipos penais, assim como o agravamento dos já existentes, que se pode encaixar no marco geral da restrição, ou a "reinterpretação" das garantias clássicas do Direito Penal substantivo e do Direito Processual Penal. Criação de novos "bens jurídicopenais", ampliação dos espaços de riscos jurídico-penalmente relevantes, flexibilização de regras de imputação e relativização dos princípios políticocriminais de garantia, não seriam mais do que aspectos dessa tendência geral, à qual cabe referir-se com o termo de "expansão" (SILVA SÁNCHEZ, 2002, p. 21).
\end{abstract}

Para Carla Caldas Fontenele Brizzi (2008, p. 5101), tal tendência "é um fenômeno eminentemente econômico" e "configura-se pela existência de blocos de criminalidade". Dessa maneira, em um mundo de economia globalizada, a criminalidade que emerge dessa 
fase do modelo econômico também ultrapassa as fronteiras estatais e atinge diversos países.

A estreita relação entre o crime e a economia capitalista já era abordada por Karl Marx (apud JINKINGS, 2007, p. 6), no século XIX, ao evidenciar a utilidade do crime para as forças produtivas, seja por sua função de estímulo à inovação dos mecanismos de defesa da propriedade, seja por retirar parte da população supérflua do mercado de trabalho e por absorver, no seu enfretamento, outra parcela dessa população.

Contemporaneamente, diante da influência neoliberal e da ausência de conquistas típicas do Estado de Bem-Estar Social, como nos países centrais da Europa, o Brasil e outros países da América Latina têm forjado sistemas penais em que o uso excessivo da sanção criminal mostra-se incapaz de proporcionar maior tranquilidade social. Em vez de garantir a responsabilização e a ressocialização do indivíduo em conflito com a lei e de reduzir o índice de delitos, o enrijecido aparato penal tem perdido legitimidade, representando algo negativo à sociedade.

O Brasil possui a quarta maior população carcerária do mundo (BRASIL..., 2015). Uma constatação recorrente dos diagnósticos e estudos sobre a temática é a de que o país passa por um momento de "hiperencarceramento", caracterizado pela focalização do encarceramento sobre grupos sociais específicos ou, ainda, pela punição de forma mais acentuada sobre alguns tipos de crimes (BRASIL, 2015, p. 12).

Outra face dessa realidade é o crescimento da violência e da letalidade policial no Brasil. Segundo dados do Anuário de Segurança Pública de 2014, ao menos 6 (seis) pessoas foram mortas por dia por policiais no ano de 2013 (MARTíN, 2014, p. 1). Os agentes policiais brasileiros mataram, em cinco anos, 11.197 (onze mil, cento e noventa e sete) pessoas, o que corresponde a mais vítimas que as polícias norte-americanas em três décadas (MARTíN, 2014, p. 1).

Uma pesquisa realizada pelo Instituto Datafolha, em julho de 2015, por encomenda do Fórum Brasileiro de Segurança Pública, revelou que 62\% (sessenta e dois porcento) dos moradores de cidades com mais de cem mil habitantes têm medo de sofrer agressão da Polícia Militar (TUROLLO JUNIOR, 2015, p. 1). Contraditoriamente, metade dos entrevistados respondeu concordar com a ideia de que "bandido bom é bandido morto" (PAGNAN, 2015, p. 1). 
Em relação à atuação estatal no âmbito penal, Raúl Eugênio Zaffaroni (2002, p. 66) elenca assertivas bastante reproduzidas no atual contexto:

\begin{abstract}
"As penas mais graves diminuem o número de delitos". "Punindo os ladrões tutela-se a propriedade". "Os loucos são perigosos". "O reincidente é mais perigoso que o primário". "A pena dissuade". "A execução penal ressocializa". "Todos são iguais perante a lei". "O legislador é o único que estabelece penas". "A intervenção punitiva tem efeito preventivo". "A prisão preventiva não é uma pena". "Se se tipifica uma conduta, sua freqüência diminui". "O consumidor de drogas proibidas converte-se em delinquente". "Todo consumidor de tóxicos é um traficante em potencial". "A impunidade é a causa da violência". "A pena estabiliza o direito".
\end{abstract}

Tratam-se de afirmações a respeito da realidade do comportamento humano, não submetidas à verificação, mas que costumeiramente são consideradas verdadeiras no Direito Penal, sem a preocupação elementar de análise e comprovação científica. A multiplicação dessas ideias na sociedade, mesmo que de forma inconsequente e acrítica, acaba por legitimar e sugerir uma expansão do Direito Penal.

Na prática, o que se nota é um Direito Penal simbólico, que confunde as verdadeiras causas da criminalidade: inúmeros problemas sociais estruturais e conjunturais.

A hiperinflação das leis penais, por exemplo, leva o Estado a tentar resolver a "patologia social" por intermédio do Direito Penal, banalizando a sua aplicação. Por fim, atacam-se as consequências da criminalidade, deixando sem solução suas verdadeiras causas.

\begin{abstract}
A legislação penal simbólica tem na sua própria existência a sua principal virtude, visto que representa ações expressivas, catárticas, no sentido de censurar o crime e confortar o público, uma vez que são aprovadas no calor da indignação popular em face de crimes violentos marcantes. Daí referir Garland (2005) que dita legislação tem o selo de qualidade "feita para a televisão", uma vez que sua preocupação principal é demonstrar que, em reação ao sentimento de indignação do público, o Estado está disposto a usar seus poderes para manter a lei, a ordem e proteger o público cumpridor da lei (WERMUTH, 2011, p. 146-147).
\end{abstract}

Outro ponto a se observar é que, cada vez mais, o Direito Penal busca compor normas de ramos diversos do Direito, assumindo uma característica híbrida, como um mosaico jurídico (FROTA JÚNIOR; DINIZ, 2007, p. 4). Essas intervenções visam a dar maior respeito e eficácia ao cumprimento de medidas dos outros ramos do Direito que não o Direito Penal, ainda que de maneira simplista e, por vezes, sem resultados práticos. 
Entre os exemplos das áreas jurídicas atingidas pela expansão do Direito Penal, cabe mencionar a criminalização nas relações de consumo, a ampliação da punição nas leis de trânsito, o rigor dos crimes referentes à pirataria e a maior vigilância dos indivíduos.

Alerta-se, ainda, que a tendência do expansionismo penal vai além de ampliar a aplicação da lei criminal: age como resposta às demandas da sociedade e traz à tona o pensamento de que, quanto mais severa a pena, maior será sua capacidade de coibir a criminalidade.

Nesse sentido, a cada nova situação de urgência, levanta-se a solução da criminalização, justificando a opção pela repressão e pela flexibilização de direitos e garantias individuais.

No artigo a "Globalização e a expansão do Direito Penal", Aureliano Coelho Ferreira exemplifica o aumento das bases penais a partir de referências recentes da legislação brasileira:

A Lei 8.038 de 1990, que culminou no agravamento do tratamento de diversos delitos classificados como hediondos. Em alguns casos, a exacerbação foi de tal monta que é possível vislumbrar delitos em que a pena mínima é superior a 30 (trinta) anos de prisão, muito embora seja esse o limite máximo para o cumprimento da pena. Outro exemplo dessa característica se encontra na Lei 11.343 de 2006 (nova Lei de Drogas), a qual, embora reduza substancialmente a punição do indivíduo que porta drogas para uso próprio, agravou exponencialmente a pena pela prática do crime de tráfico, previsto no art. 33 do referido diploma legal. Antes com uma pena mínima de 03 (três) anos de reclusão, possibilitando, inclusive, a conversão da pena privativa de liberdade em restritiva de direitos (ao menos após a modificação da jurisprudência nacional e posteriormente da lei de crimes hediondos, circunstância já referidas alhures), a nova Lei fixou a reprimenda base em 05 (cinco) anos de reclusão. Não bastasse isso, dentre outras circunstâncias, veda o legislador a concessão de liberdade provisória, conquanto se caracterize facilmente como uma medida de caráter inconstitucional, já que desconsidera as condições do caso concreto, impingindo ao pequeno traficante e ao traficante internacional os mesmos institutos repressivos (FERREIRA, 2009, p. 2).

Constata-se, ademais, uma maior identificação/solidarização da coletividade com as vítimas de delitos, em decorrência do medo de ser tornar uma delas (WERMUTH, 2011, p. 136).

Com isso, deixa-se de ver no Direito Penal um instrumento de defesa dos cidadãos em face do arbítrio punitivo estatal - ou seja, como Carta Magna do delinquente - e passa-se a percebê-lo como Carta Magna da vítima, o que redunda em um consenso restritivo quanto aos riscos permitidos, dado que o 
sujeito que se considera vítima potencial de um delito não aceita a consideração de determinados riscos como permitidos (WERMUTH, 2011, p. 136-137).

O expansionismo penal relaciona-se profundamente com o discurso midiático, na medida em que este reproduz a crença de que punições mais severas são capazes de solucionar a criminalidade.

\section{O papel da mídia e o controle social}

Para uma adequada caracterização da mídia na atualidade, deve-se considerar o contexto de evolução dos meios de comunicação nas últimas décadas. Dia após dia, a tecnologia da comunicação amplia sua capacidade de alcançar mais pessoas e de transmitir informações com maior agilidade.

A troca de informações, dessa forma, alcança um novo patamar, que ainda não chegou ao ápice de sua potencialidade. Isso fica evidente, por exemplo, ao se analisar o desenvolvimento da internet e a possibilidade da confluência de diferentes tipos de mídia. Com um computador conectado à internet de alta velocidade, as pessoas podem ler notícias, escutar músicas, acessar rádios, fazer ligações, compartilhar vídeos ou assistir à grade de programação da televisão aberta.

Dessa forma, a mídia deve ser entendida a partir dos diversificados meios de transmissão de conteúdo de massa, que possuem "a capacidade de influenciar a opinião e o comportamento das pessoas e pautar a agenda política, social e cultural do país" (BARROSO, 2004, p. 23).

Outro aspecto que merece destaque na evolução dos meios de comunicação é a manutenção do modelo de concentração da grande mídia, para o qual o Estado cumpriu, historicamente, um papel decisivo em assegurar a propriedade e o uso dos meios de comunicação de massa pela iniciativa privada.

As últimas décadas acentuaram, no Brasil e na América Latina, o traço histórico de concentração de expressiva parcela dos meios de comunicação nas mãos de um reduzido número de megagrupos. A moldura de concentração prospera em meio à digitalização de sistemas, redes e plataformas de produção, transmissão e recepção de dados, imagens e sons. As infotelecomunicações (palavra que utilizo para designar a convergência tecnológica entre os setores de informática, telecomunicações e mídia) asseguram as condições objetivas para o crescimento exponencial da oferta de canais, produtos, serviços e conteúdos. Só que essa vocação expansiva se consolida sob controle, influência e lucratividade de poucas 
corporações, via de regra globais, ou nacionais e regionais em alianças estratégicas ou parcerias com gigantes transnacionais (MORAES, 2013, p. 1).

Com o desenvolvimento tecnológico dos meios de comunicação, bem como com a manutenção de um modelo concentrador na mão dos "donos da notícia", a imprensa alcança uma autonomia muito grande na sociedade atual, passando a exercer um poder social que, por vezes, faz do cidadão não um destinatário, mas um refém da informação.

Por meio da seleção de conteúdos e de abordagens, a mídia tem o poder da construção da realidade, que é um poder simbólico, compreendido como poder decorrente do monopólio ou da luta para estabelecer um monopólio sobre um discurso, traduzido numa luta pela "verdade" e pelos seus efeitos (ROCHA, 2013, p. 232).

Nesse contexto, torna-se necessário defender não apenas a liberdade de imprensa, mas também a liberdade em face à imprensa (NUNES JÚNIOR, apud GUERRA, 2005, p. 246).

Na percepção de Aloísio Krohling e Raphael Boldt (2008, p. 3), os meios de comunicação,

[...] Em sua busca permanente por altos índices de audiência, [...] não apenas informa - e contraria constantemente a necessidade de imparcialidade do texto jornalístico, agregando sensações, impressões ou opiniões do emissor - mas transforma fatos corriqueiros e relativamente destituídos de relevância em casos emblemáticos, capazes de justificar o discurso criminalizante que atualmente se espraia pela sociedade, produzindo e reproduzindo o temor ao delito, estilos agressivos de comportamento e a agravação das leis penais existentes. De contravenções penais a homicídios, tudo se torna motivo para, desproporcionalmente e irresponsavelmente, promover a intervenção penal (seja através da atividade legiferante ou judicante) como o mais eficiente remédio para se combater uma doença que afeta toda a sociedade.

Dessa forma, a mídia assume um discurso de criminalização dos conflitos e promove a dramatização da violência. Reiteradas manchetes dos jornais e chamadas da televisão destacam crimes crúeis, promovendo a insegurança e o medo da população.

Há quem afirme que nunca se teve tanto medo e que este nunca assumiu uma dimensão tão onipresente (WERMUTH, 2011, p. 133). Nas palavras de Zygmunt Baumann (apud WERMUTH, 2011, p. 135), "novos perigos são descobertos e anunciados quase diariamente, e não há como saber quantos mais, e de que tipo, conseguiram escapar à nossa atenção (e a dos peritos!) preparando-se para atacar sem aviso". 
Como decorrência dessa sensação generalizada do medo, tem-se o aumento da preocupação com a criminalidade, a assumir, por vezes, contornos de "alarmismo" e de obsessão por medidas repressivas.

Conforme Arnaldo Xavier (2008, p. 276-277):

A manutenção do estado de medo faz-se necessária para legitimar a utilização do paradigma etiológico do crime, sendo fundamental manter o sentimento do perigo (sentimento subjetivo de insegurança), gerando indignação e consensos silenciosos entre os setores sociais.

A violência é tomada apenas como manifestação delituosa individual, e não em sua fenomenologia global, resultante de repressão de necessidades reais e, portanto, de violação ou suspensão de direitos humanos (ANDRADE, apud XAVIER, 2008, p. 277).

O que é evidenciado pelos meios de comunicação é a busca pela punição do sujeito, não a solução do problema. Valoriza-se tudo fora de seu contexto, fazendo surgir a técnica sem finalidade (ou com finalidade em si mesma), a especialização exagerada e a visão cada vez mais individualizada das coisas, com perda da dimensão coletiva (SILVA, 2012, p. 269).

$\mathrm{Na}$ atenção do público, a violência criminal adquire a relevância que deveria corresponder à violência estrutural (ANDRADE, apud XAVIER, 2008, p. 277). A mensagem é que o Estado brasileiro está em uma constate guerra com os criminosos. Tal discurso midiático, muitas vezes sem qualquer comprovação científica, apenas reforça a leviana conclusão de aumento da criminalidade (FERREIRA, 2009, p. 4).

Consequência disso é a legitimação da ideologia que sustenta o recrudescimento das regras penais. Afinal, no discurso hegemônico da imprensa, e também das instituições, o diagnóstico está pronto: o aumento da violência (criminalidade) resulta da soma do comportamento individual desviante com a impunidade (XAVIER, 2008, p. 278).

Ademais, o discurso midiático produz e reproduz preconceitos e estereótipos que estigmatizam as populações mais pobres. "O criminoso, quase sempre associado às classes subalternas, torna-se o bode expiatório da situação e passa de cidadão a inimigo" (KROHLING; BOLDT, 2008, p. 17).

Fernanda Rios Petrarca (2007, p. 2) alerta para a relação entre a mídia e o Direito, na medida em que os processos de construção das notícias estabelecem categorias como "o criminoso", "o crime", "a justiça" e "o direito". 
$\mathrm{Na}$ prática da atividade jornalística, a escolha da notícia, na maioria das oportunidades, é baseada naquilo que se identifica como o sensacional, o espetacular, o excepcional. E, nesse caso, o crime ganha mais evidência (PETRARCA, 2007, p. 2).

\begin{abstract}
A busca do sensacional e do espetacular, do "furo" jornalístico, é o princípio de seleção daquilo que pode e daquilo que não pode ser mostrado, o que é definido pelos índices de audiência - ou seja, pela pressão do campo econômico, do mercado, sobre os jornalistas. E as imagens, aliadas às legendas que dizem o que é preciso ler e compreender, produzem o efeito de real, ou seja, fazem ver e fazem crer no que fazem ver (WERMUTH, 2011, p. 143).
\end{abstract}

Para efeitos da análise empreendida neste artigo, cabe destacar dois desdobramentos importantes na relação entre o Direito e a mídia, identificados por Petrarca. O primeiro é o efeito que a imprensa produz nos leitores, uma vez que, ao noticiar eventos como um crime, a mídia contribui para fornecer quadros de interpretação ao leitor sobre o sistema penal, sobre o crime, sobre o criminoso na sociedade e sobre as próprias vítimas.

\footnotetext{
A imprensa, de modo geral, sugere "como pensar" os assuntos oferecendo aos leitores compreensões sobre os temas noticiados. Ao mesmo tempo, ela também intensifica a legitimidade do sistema penal, reforçando o seu papel na sociedade. As matérias fornecem imagens e representações sobre o agressor, o qual pode eventualmente ser definido como "doente mental", ou como assassino, e sobre as vítimas, que por vezes podem ser apontadas como estimuladoras da situação (PETRARCA, 2007, p. 4).
}

O segundo desdobramento é o efeito que a mídia exerce sobre o campo jurídico. Nessa linha de pensamento, a mídia pode afetar legisladores, julgadores, jurados etc., quando, por meio da divulgação intensiva de certos crimes, promove-se um debate público capaz de influenciar decisivamente tais setores (PETRARCA, 2007, p. 5).

É necessário se perguntar: qual a relação entre o Direito e a mídia? Qual o papel dos meios de comunicação de massa na sociedade atual? E nas instituições judiciais? Seguramente, a grande mídia não pode ser considerada somente meio de divulgação de informações. Mais do que isso, trata-se de uma instituição com dimensões econômicas, políticas e culturais, e que tem poder de articulação do conjunto do sistema financeiro, de formulação da agenda política e de formação da opinião pública (SILVA, 2012, p. 14). 
É nesse cenário de relações complexas que a mídia pode ser classificada como um "instrumento informal de controle do delito", ou seja, um instrumento consubstanciado na sociedade civil, que atua de forma mais sutil e que perdura por toda a vida do cidadão, de forma a discipliná-lo e a inseri-lo na sociedade (CAMACHO, 2015, p. 2).

A mídia, assim, exprime a ideologia dominante, conformando a conduta dos indivíduos com o modelo por ela empregado, bem como selecionando os fatos que, de certo modo, atingem os interesses das classes mais altas (CAMACHO, 2015, p. 3).

O discurso midiático em tom populista prega a repressão penal e a criminalização de determinadas condutas e parcelas da população, sendo a juventude pobre dos países periféricos a principal prejudicada.

\section{A criminalizaçãço da juventude e a redução da idade penal}

É possível perceber, particularmente, nos países periféricos, a existência de um claro processo de seleção de grupos identificados como delinquentes (ZAFFARONI, 2009, p. 56), em que "o controle social tende a ser mais anestésico entre as camadas sociais mais privilegiadas e que adotam os padrões de consumo dos países centrais" (ZAFFARONI, 2009, p. 58).

Destaca-se, nesse sentido, o movimento de criminalização da juventude pobre, na medida em que o sistema jurídico penal mostra-se mais rigoroso para aqueles delitos cometidos, na maioria das vezes, por camadas marginalizadas. Esses são crimes com maior visibilidade, embora não representem, necessariamente, situações de maior risco para a sociedade como um todo.

Consoante ao que foi abordado no tópico anterior, a mídia corrobora a manutenção de tal modelo. Por vezes, os veículos de comunicação assumem o papel ideológico que mascara a realidade com a falsa ideia de igualdade e de neutralidade contida no sistema jurídico vigente (BATISTA, 2007, p. 33). E vão além, ao legitimarem a ordem estabelecida, considerando o episódio criminal como episódio individual; e a ordem legal, como ordem natural, respaldada pela sociedade (BATISTA, 2007, p. 30).

Tanto para a mídia quanto para o Estado, o foco das atenções e o peso das medidas repressivas não consideram, da mesma maneira, as diferentes parcelas da sociedade. 0 jovem pobre, negro e do sexo masculino constitui um "tipo ideal" de criminoso no 
imaginário social contemporâneo, uma vez que, no processo social de criminalização, observa-se a construção de uma base legítima para o aumento da repressão e da violência com relação a essa população (ALMEIDA, 2008, p. 11585).

Nesse cenário, emergem propostas como a redução da maioridade penal. "Aos adolescentes infratores é atribuído esse papel de encarnação do mal absoluto que precisa ser combatido para restauração da ordem perdida" (ALMEIDA, 2008, p. 11586).

Apesar da redução da idade penal não ser um tema novo para os países da América Latina, ela ainda representa uma bandeira em disputa no continente. Isso pode ser exemplificado nas manchetes da imprensa sobre o tema: "Uruguai rejeita redução de maioridade penal e terá segundo turno entre Vázquez e Lacalle Pou" (URUGUAI..., 2014); "Redução da maioridade penal volta a ser tema pré-eleitoral na Argentina" (YOFRE, 2013); "Dilma e Aécio brigam por redução da maioridade penal" (BORDIN, 2014).

A maioridade penal, no Brasil, é determinada aos dezoito anos de idade (BRASIL, 1988), sendo um indicativo biológico e cronológico recomendado por estudiosos e legisladores como marco do aparecimento da compreensão do injusto e da autodeterminação pelo adolescente.

A definição da idade limite não é um padrão no mundo. A escolha dessa idade leva em consideração as culturas jurídica e social, como também a maturidade emocional, mental e intelectual dos jovens de cada nação (OLIVEIRA, 2010, p. 21).

A idade mínima para a responsabilidade penal é de sete anos na Austrália, Egito, Kuwait, Suíça e Trinidad e Tobago; oito anos na Líbia; nove anos no Iraque; dez anos na Malásia; 12 anos no Equador, Israel e Líbano; 13 na Espanha, 14 na Armênia, Áustria, China, Alemanha, Itália, Japão e Coréia do Sul; 15 na Dinamarca, Finlândia e Noruega; 16 anos na Argentina, Chile, Portugal e Cuba; 17 anos na Polônia e 18 na Colômbia, Peru e em Luxemburgo (ANDRADE, apud OLIVEIRA 2010, p. 2).

Existem, inclusive, países que experimentaram a redução da maioridade penal e depois voltaram atrás.

70\% dos Países do Mundo adotam a idade Penal de 18 anos, e ainda afirma que Países como a Alemanha e a Espanha, que reduziram a idade Penal no início da década passada, verificaram um aumento da criminalidade entre os adolescentes e acabaram voltando a estabelecer a idade Penal aos 18 anos e ainda adotaram um tratamento especial para os jovens de 18 a 21 anos (ANDRADE, apud OLIVEIRA, 2010, p. 2). 
Tais experiências são esclarecedoras no que se refere à incapacidade de a redução da maioridade penal mudar significativamente a questão da criminalidade, uma vez que não enfrenta as reais causas desse fenômeno.

A redução da idade para responsabilidade penal, compreendida no âmbito do expansionismo do Direito Penal, impõe à sociedade um modelo de justiça juvenil calcado na crescente exclusão dos adolescentes do convívio social para serem "guardados" em unidades de internação.

Sem apoio social, psicológico e pedagógico, esses jovens são isolados da sociedade, vivenciando um cotidiano de violência (torturas físicas e psicológicas) e de violação de direitos (vida, integridade física e educação).

A lógica do rebaixamento penal para adolescentes, de acordo com Ângela Pinheiro (2004, p. 353), fortalece a concepção de que crianças e adolescentes são objetos de repressão social. Para a autora, tendo como referência o histórico da legislação brasileira, permanece no imaginário da população e dos operadores jurídicos a ideia de que crianças e adolescentes, uma vez não absorvidos pelo mercado de trabalho ou não adaptados às relações sociais hegemônicas (consumo, família, cultura etc.), são uma ameaça e devem ser retirados do convívio em sociedade (PINHEIRO, 2004, p. 353).

Assim, apesar da existência do Estatuto da Criança e do Adolescente (ECA), há uma tendência de recrudescimento das medidas punitivas sobre a população juvenil, nos mesmos moldes do que ocorre atualmente com as políticas punitivas dirigidas aos adultos (BRASIL, 2015, p. 12).

\section{Considerações finais}

Diante do exposto, percebe-se que a tendência atual de expansão do Direito Penal e a busca por soluções mais punitivas, com o pretexto da superação da situação de violência, acabam por reprimir e criminalizar a juventude dos países.

Como fenômeno mundial, o expansionismo penal reflete-se na hiperinflação das leis penais, na maior intervenção do Direito Penal em outros ramos do Direito, na definição de medidas drásticas em resposta ao clamor social e na difusão de um sentimento de insegurança e de injustiça, potencializado pela dramatização da violência pelos meios de comunicação. 
A grande mídia estimula o processo de alarde social que influencia forças políticas e aguça campanhas de "lei e ordem", as quais reforçam a estigmatização e a falsa representação de solidariedade a unificar todos os cidadãos na luta contra o "inimigo interno" comum (BARATTA, 2002, p. 224).

A consequência disso é a reprodução de um discurso favorável à redução da maioridade penal, que consolida, na opinião pública, a equivocada ideia de que a expansão e o recrudescimento legislativo são capazes de resolver o problema da violência.

$\mathrm{Na}$ prática, o que pode ocorrer é o inverso: o agravamento da situação da criminalidade e do desrespeito de direitos de crianças e adolescentes.

\section{Referências}

ALMEIDA, B. G. M. Medo do crime e criminalização da juventude. In: CONGRESSO NACIONAL DE EDUCAÇÃO DA PUCPR; 8.; CONGRESSO IBERO-AMERICANO SOBRE VIOLÊNCIAS NAS ESCOLAS - CIAVE, 3., 2008, Curitiba. Anais... Curitiba: Champagnat, 2008. p. 11582-11594.

BARATTA, A. Criminologia crítica e crítica do direito penal. 3. ed. Rio de Janeiro: Freitas Bastos, 2002.

BARROSO, L. R. Tourada aos domingos - da necessidade de regulação da comunicação social no Brasil para proteção da soberania e da cultura nacional. Revista Fórum, Rio de Janeiro, p. 23, 2004.

BATISTA, N. Novas tendências do direito penal. 2003. Disponível em: $<$ http://www.buscalegis.ufsc.br/revistas/files/anexos/12648-12649-1-PB.htm>. Acesso em: 8 mar. 2015.

Introdução crítica ao direito penal Brasileiro. 11. ed. Rio de Janeiro: Revan, 2007.

BORDIN, L. B. Dilma e Aécio brigam por redução da maioridade penal. Gazeta do Povo, Curitiba, 15 out. 2014. Disponível em: <http://www.gazetadopovo.com.br/vidapublica/eleicoes/2014/dilma-e-aecio-brigam-por-reducao-da-maioridade-penaleexj5qh718ee42jx7dw3gc8r2>. Acesso em: 8 mar. 2015.

BRASIL. Presidência da República. Constituição da República Federativa do Brasil de 1988. 5 out. 1988. Disponível em:

<http://www.planalto.gov.br/ccivil_03/Constituicao/Constituicao.htm>. Acesso em: 8 mar. 2015.

Presidência da República. Secretaria Geral. Mapa do encarceramento: os jovens do Brasil. Brasília: Presidência da República, 2015. Disponível em: 
<http://www.pnud.org.br/arquivos/encarceramento_WEB.pdf>. Acesso em: 10 out. 2015.

BRASIL tem 4ạ maior população carcerária do mundo, diz estudo do MJ. UOL. 23 jun. 2015. Disponível em: <http://noticias.uol.com.br/cotidiano/ultimasnoticias/2015/06/23/prisoes-aumentam-e-brasil-tem-4-maior-populacao-carceraria-domundo.htm>. Acesso em: 10 out. 2015.

BRIZZI, C. C. F. A globalização e os novos paradigmas do direito penal no combate ao terrorismo. In: CONGRESSO NACIONAL DO CONPEDI, 16., 2007, Belo Horizonte. Anais... Florianópolis: Fundação Boiteux, 2008. p. 5099-5115. Disponível em:

$<$ http://www.conpedi.org.br/manaus/arquivos/anais/bh/carla_caldas_fontenele_brizzi.p df>. Acesso em: 8 mar. 2015.

CAMACHO, M. G. Controle social do delito, mídia e expansionismo penal na sociedade contemporânea. 2015. Disponível em:

<http://matheuscamacho.jusbrasil.com.br/artigos/155755014/controle-social-do-delitomidia-e-expansionismo-penal-na-sociedade-contemporanea>. Acesso em: 8 mar. 2015.

DINIZ NETO, E. Sociedade de Risco, Direito Penal e Política Criminal. Revista de Direito Público, Londrina, v. 5, n. 2, p. 202-220, 2010. Disponível em:

<http://www.uel.br/revistas/uel/index.php/direitopub/article/view/7385>. Acesso em: 10 out. 2015.

FERREIRA, A. C. Globalização e a expansão do Direito Penal. 2009. Disponível em:

<http://www.conteudojuridico.com.br/?artigos\&ver=2.24939>. Acesso em: 8 mar. 2015.

FROTA JÚNIOR, G. N. C.; DINIZ, A. S. Expansão do poder punitivo estatal e estudo do Direito Penal mínimo. 2007. Disponível em:

$<$ http://www.fa7.edu.br/recursos/imagens/File/direito/ic/v_encontro/expansaodopoder punitivo.pdf>. Acesso em: 8 mar. 2015.

GUERRA, S. Breves considerações sobre os limites da liberdade de imprensa. Revista Faculdade de Direito de Campos, Campos, v. 6, n. 6, 2005. Disponível em:

<http://fdc.br/Arquivos/Mestrado/Revistas/Revista06/Docente/11.pdf>. Acesso em: 8 mar. 2015.

JINKINGS, I. A penalização da miséria no Estado neoliberal. In: ENCONTRO DA ASSOCIAÇÃO NACIONAL DE PÓS-GRADUAÇÃO E PESQUISA EM PLANEJAMENTO URBANO E REGIONAL, 12., 2007, Belém. Anais... Belém: Associação Nacional de Pós-Graduação e Pesquisa em Planejamento Urbano e Regional, 2007. p. 1-19. Disponível em: <http://unuhospedagem.com.br/revista/rbeur/index.php/anais/article/ view/2371/23>. Acesso em: 10 out. 2015.

KROHLING, A.; BOLDT, R. Entre cidadãos e inimigos: o discurso criminalizante da mídia e a expansão do Direito Penal como instrumentos de consolidação da subcidadania. Revista Direitos Fundamentais e Democracia, Curitiba, v. 4, n. 1, p. 16-30, 2008. 
MARTÍN, M. Brasil tem seis assassinatos por hora, a maioria de homens negros. El País: o jornal global, 2014. Disponível em: <http://brasil.elpais.com/brasil/2014/11/11/ politica/1415732921_778564.html>. Acesso em: 10 out. 2015.

MORAES, D. Por que a concentração monopólica da mídia é a negação do pluralismo. Observatório da Imprensa, São Paulo, v. 19, n. 881, 2013. Disponível em: <http://www.observatoriodaimprensa.com.br>. Acesso em: 8 mar. 2015.

MUÑOZ CONDE, F. As reformas da parte especial do Direito Penal espanhol em 2003: da "tolerância zero" ao "direito penal do inimigo". Revista Eletrônica de Ciências Jurídicas, São Luís: RECJ, jan. 2005.

OLIVEIRA, J. R. A redução da maioridade penal diante da criminalidade infantil. 2010. $77 f$. Trabalho de Conclusão de Curso (Graduação em Direito) - Faculdade Capixaba de Nova Venécia, Nova Venécia, 2010.

PAGNAN, R. Metade do país acha que "bandido bom é bandido morto", aponta pesquisa. Folha de São Paulo, Caderno Cotidiano, São Paulo, 5 out. 2015. Disponível em: <http://www1.folha.uol.com.br/cotidiano/2015/10/1690176-metade-do-pais-acha-quebandido-bom-e-bandido-morto-aponta-pesquisa.shtml>. Acesso em: 1 out. 2015.

PETRARCA, F. R. As relações entre Mídia e Direito no Brasil: elementos para uma análise sociológica. Revista Sociologia Jurídica, v. 1, p. 1-12, 2007.

PINHEIRO, A. A. A. A criança e o adolescente, representações sociais e processo constituinte. Psicologia em Estudo, Maringá, v. 9, n. 3, p. 343-355, 2004. Disponível em: <http://www.scielo.br/pdf/pe/v9n3/v9n3a02.pdf>. Acesso em: 8 mar. 2015.

ROCHA, A. F. O. Sistema penal e mídia: luta por poder simbólico. Revista do CEJUR/TJSC: Prestação Jurisdicional, Florianópolis, v. 1, n. 1, p. 225-242, 2013. Disponível em: <http://revistadocejur.tjsc.jus.br/cejur/article/view/33>. Aceso em: 11 out. 2015.

SILVA, E. W. Sociologia jurídica. ljuí: Unijuí, 2012.

SILVA SÁNCHEZ, J.-M. A expansão do direito penal: aspectos da política criminal nas sociedades pós-industriais. 2. ed. São Paulo: Revista dos Tribunais, 2002.

TUROLLO JUNIOR, R. Maioria da população diz ter medo da Polícia Militar, aponta Datafolha. Folha de São Paulo, Caderno Cotidiano, São Paulo, 31 jul. 2015. Disponível em: <http://www1.folha.uol.com.br/cotidiano/2015/07/1662655-maioria-da-populacao-dizter-medo-da-policia-militar-aponta-datafolha.shtml>. Acesso em: 10 out. 2015.

URUGUAI rejeita redução de maioridade penal e terá segundo turno entre Vázquez e Lacalle Pou. Opera Mundi, Caderno Notícias, São Paulo, 27 out. 2014. Disponível em: <http://operamundi.uol.com.br/conteudo/noticias/38331/uruguai+rejeita+reducao+de+ maioridade+penal+e+tera+segundo+turno+entre+vazquez+e+lacalle+pou.shtml $>$. Acesso em: 8 mar. 2015. 
WERMUTH, M. A. D. Medo, direito penal e controle social. Revista da Faculdade de Direito de Uberlândia, Uberlândia, v. 39, n. 1, p. 133-168, 2011. Disponível em: <http://www.seer.ufu.br/index.php/revistafadir/article/view/18376>. Acesso em: 10 out. 2015.

XAVIER, A. A construção do conceito de criminoso na sociedade capitalista: um debate para o Serviço Social. Revista Katálysis, Florianópolis, v. 11, n. 2, p. 274-282, 2008.

Disponível em: <https://periodicos.ufsc.br/index.php/katalysis/article/viewFile/S141449802008000200013/8328>. Acesso em: 10 out. 2015.

YOFRE, F. Redução da maioridade penal volta a ser tema pré-eleitoral na Argentina. Opera Mundi, Caderno Notícias, São Paulo, 5 out. 2013. Disponível em:

$<$ http://operamundi.uol.com.br/conteudo/noticias/31599/reducao+da+maioridade+pena I+volta+a+ser+tema+pre-eleitoral+na+argentina.shtml>. Acesso em: 8 mar. 2015.

ZAFFARONI, E. R. Manual de Direito Penal Brasileiro: parte geral. 3. ed. São Paulo: Revista dos Tribunais, 2002.

. Manual de direito penal brasileiro. 8. ed. São Paulo: Revista dos Tribunais, 2009. v. 1 